Mark Bland. A Guide to Early Printed Books and Manuscripts. Chichester, U.K.: Wiley-

Blackwell, 2010. x, 236p. ISBN 9781405124126. \$104.95

A Guide to Early Printed Books and Manuscripts is a thin volume. Given the cost of the book, I expected a massive volume, rich with full-color illustrations. When the book arrived in my mailbox, I was surprised to discover, after a cursory glance, that not only was it brief in length but that the few illustrations present were black and white. However, upon further review, I realized that its length is easily compensated for by the density and quality of content found within it.

Within his first paragraph, Bland states that this book was written to complement Gaskell's A New Introduction to Bibliography. ${ }^{4}$ The primary distinction between the two is that, whereas Gaskell focuses on the mechanics of how books are put together, this book is intended to explain how to look at the book and interpret it (p. 10). Although the two books differ in approach, Bland's book does share one notable characteristic with Gaskell's: neither is easy to digest for the novice in the field of bibliography. The back of the dust jacket describes Bland's work as "essential reading for anyone interested in book history and textual scholarship." However, the complexity of concepts described in both books leaves me inclined to recommend them to more advanced scholars, rather than as introductory texts for new students of book history. I recognize that Gaskell's book is a seminal text in the field, and Bland certainly provides a wealth of information in interpreting the book as object. Nonetheless, both presume a higher level of comprehension that is more easily digested by experienced professionals than by beginners.

In terms of composition, the book is not particularly aesthetically appealing. Sections tend to blend into each other with no clear delineations, and trying to read it for any length of time is like attempting to read early Latin text without spacing or punctuation. Although our predecessors may have done so quite successfully, the effect is somewhat cumbersome to the modern reader.

Strangely, Bland indicates in his introductory chapter that the focus of this book is the late $16^{\text {th }}$ to early 17 th centuries, a choice he says he made because examples from that period best illustrate the concepts he intends to discuss. While this is perfectly valid reasoning for focusing on that period, it makes the choice of title a bit misleading. It seems odd to write a book on "early printed books," but then neglect the first $100+$ years of printing history.

Bland accomplishes his objective in demonstrating how to interpret the characteristics of the physical book rather than focusing on the mechanics of its compo-

4. Philip Gaskell, A New Introduction to Bibliography (Oxford: Clarendon Press, 1974). 
nents and structures. For example, in the second chapter, he addresses not just the processes involved in paper-making but also what can be determined about the paper based on characteristics like watermark analysis. In this section, he provides a useful list of "five pieces of information that a bibliographer needs to establish when studying paper" (p. 35). Gaskell offers more description of collation formulae and other concepts related to the mechanics of book production, but Bland's focus is less on knowing how to create a formula and more on evaluating what that formula might mean in the lifetime of that particular book.

The most powerful sections of the book are found in the opening and closing chapters, when Bland provides a lovely defense of the importance of the original object over digital images or other reproductions. His first argument in the chapter entitled "A Guide for the Perplexed" defends the maintenance of multiple copies of a work:

To understand why some things may be unusual, it is necessary to have a feeling for what is conventional, and the only way to do this is to handle the original items, and a lot of them. ... It is not unusual to find that one copy of a printed book may have details about its earliest price or date of publication; another, a gift binding; a third may have marginalia, or an interesting provenance: cumulatively, copy-specific details build up a more complex picture than that which any one volume might present (p. 2).

As the digital collections in our institutions continue to grow, and our space and financial resources decline, it can be a challenge to build a case for retaining a single physical copy of a given work. Bland demonstrates the importance of preserving not just a single copy but as many copies as possible. In the final chapter, "Last

\section{INDEX TO ADVERTISERS}

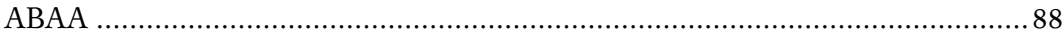

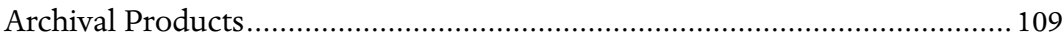

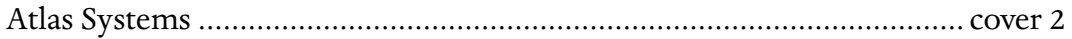

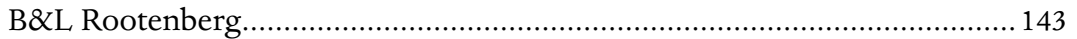

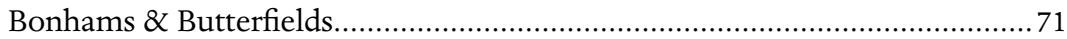

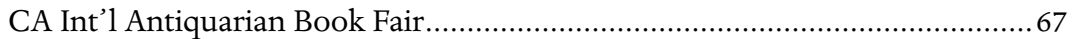

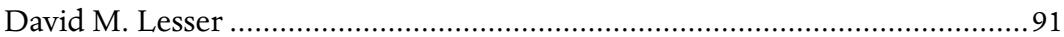

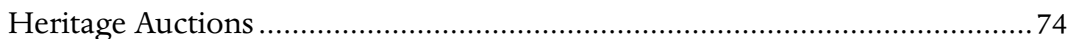

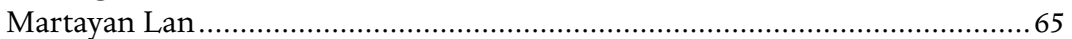

Philadelphia Rare Books \& Manuscripts ....................................................... cover 4

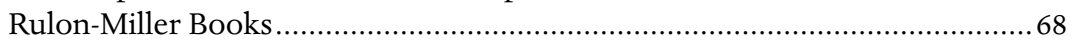

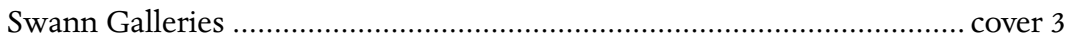

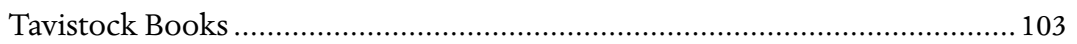


Words," Bland does a splendid job of reinforcing the importance of the book as object. The chapter is filled with persuasive imagery, and I would not do justice to the book to isolate a single quotation from it here. All I can say is that anyone in search of a reason to defend the preservation of the physical book as object would be well served to refer to this volume. Bland frames the argument eloquently with his first and last chapters. It seems a shame that the remainder of the text becomes a victim of its own physical form.

Overall, I felt that the fault in the book lies not in the content but in the presentation of that content. As I mentioned earlier, Bland's objective is guiding the reader in how to look at a book and interpret what that material object is telling him or her. Ironically, however, his compelling discussion of bibliographic interpretation is somewhat obscured by the physical arrangement of the book itself. But, presentation aside, I would recommend the book to two distinct audiences: anyone who is interested in applying his or her discipline-specific knowledge of bibliography to the interpretation of the book and its physical form or someone in search of a compelling argument for the preservation of the book as a material object. - Jennifer K. Sheehan, Ph.D., Curator, Rare Books, University of North Texas Libraries

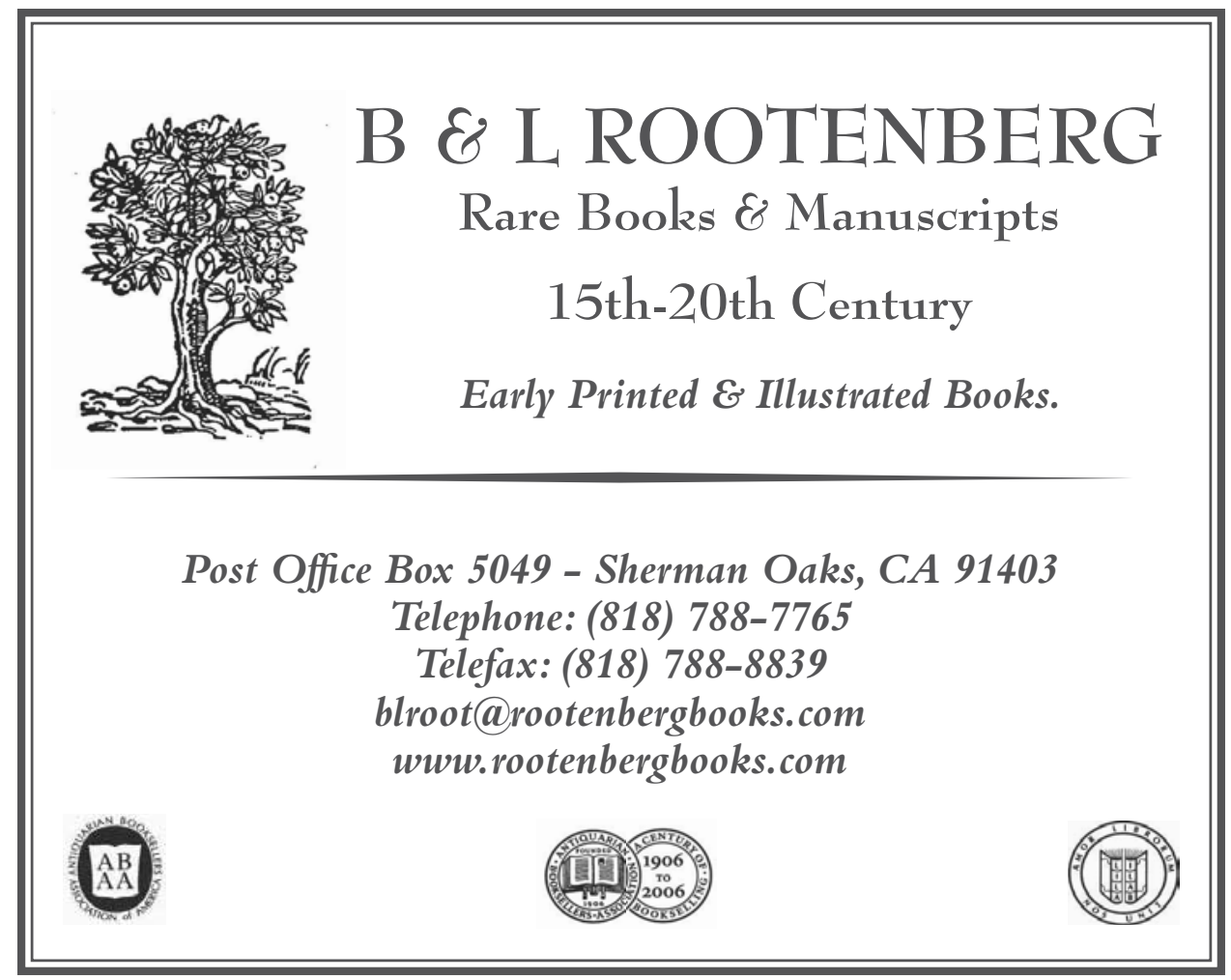

